\title{
IMPROVING QUALITY AND INCLUSIVE EDUCATION ON PHOTOGRAMMETRY: NEW TEACHING APPROACHES AND MULTIMEDIA SUPPORTING MATERIALS
}

\author{
G. Tucci ${ }^{1 *}$, E. I. Parisi ${ }^{1}$, V. Bonora ${ }^{1}$, L. Fiorini ${ }^{1}$, A. Conti ${ }^{1}$, M. Corongiu ${ }^{1}$, J. P. Ortiz-Sanz ${ }^{2}$, M. Gil-Docampo ${ }^{2}$, T. Rego- \\ Sanmartín ${ }^{3}$, M. Arza-García ${ }^{2}$ \\ ${ }^{1}$ Geomatics for Environment and Conservation of Cultural Heritage Laboratory - GECO. Dept. of Civil and Environmental \\ Engineering, University of Florence, Via di S. Marta 3, 50139, Florence, Italy - (grazia.tucci, ericaisabella.parisi, valentina.bonora, \\ lidia.fiorini, alessandro.conti, manuela.corongiu)@unifi.it \\ ${ }^{2}$ Civil and Geomatics Research Group - CIGEO. Dept. of Agroforestry Engineering. University of Santiago de Compostela, Lugo \\ (CampusTerra) 27002, Spain - (juan.ortiz, ml.gil, m.arza)@usc.es \\ ${ }^{3}$ Education, University and Vocational Training Department. Regional Government (Xunta de Galicia), Spain - \\ teresaregosanmartin@edu.xunta.es
}

\section{Commission V, WG V/1}

KEY WORDS: Smart Education, Photogrammetry, Collaborative Learning, Challenge-based Learning, Learning-By-Doing, Educational Resources, Multimedia Tools

\begin{abstract}
:
The democratization and accessibility of low-cost devices for image acquisition and the development of highly automated procedures for orientation and dense image matching allow almost every person to be a potential producer of photogrammetric models. The diffusion of image-based technologies to produce 3D models amongst wider audiences entails however some risks, as the lack of critical awareness of the final quality of the outputs. Information and education about potentialities and limitations of reality-based digitization by photogrammetry may help spreading procedures and methods for the correct use of this technology. This paper presents the results of one of the funded projects within the 2018 ISPRS Capacity Building Initiatives "Education and training resources on digital photogrammetry". The production of multimedia material for supporting smart educational teaching and learning approaches will be reported, as well as experiences on their application on case studies. Blended innovative teaching and learning pedagogical approaches have been tested, as Flipped Classroom (FC), Learning-by-doing (LBD), Collaborative Learning (CL), and Challenge-Based Learning (CBL), supported by multimedia tools for capacity-building and knowledge transfer. The implementation of multimedia materials for supporting teaching strategies resulted in the production of updated and engaging resources, as videos, tutorials, and datasets to be used during courses, workshops, and seminars targeted to different user groups. The combination of teaching strategies and multimedia supporting materials were tested within national and international projects, from academic courses to complete non-experts, from activities on the field to online and distance learning.
\end{abstract}

\section{INTRODUCTION}

The COVID-19 pandemic and the measures adopted all around the world for population containment (lock-down) has forced the adoption of distance and online learning approaches, to continue the didactic activities. The didactic provision has been overturned at all levels of education, from primary to tertiary education $^{1}$, along with an outstanding and quick adaptive capacity from both the involved sides, teachers and students.

Before these tragic events occurred, the topic of quality and inclusive education has already been part of Sustainable Development Goals for the European $2030 \mathrm{Agenda}^{2}$, as stated by Goal 4: "Ensure inclusive and equitable quality education and promote lifelong learning opportunities for all".

The necessity of directing all the previous didactic activities to online and distance learning (ODL) has highlighted with extreme strength, the inequalities still present in our society, to achieve goals 4.1 and $4.3^{3}$ : digital divide, internet accessibility, availability of adequate IT equipment (PC, tablet, etc.) still prevent for inclusive and equitable education. For what concerns quality in education, the unexpected necessity of

\footnotetext{
* Corresponding author

${ }^{1}$ According to International Standard Classification

of Education - ISCED

${ }^{2}$ www.sustainabledevelopment.un.org/sdgs

${ }^{3}$ www.ec.europa.eu/sustainable-development/goal4_en
}

adopting exclusively online and distance learning has requested an adaptation in knowledge transfer and capacity building. The new didactic tools need to assure the same level of quality as the habitual ones and to compensate for the absence of direct feedbacks. A modernization and update of supporting materials used for, but not limited to, online learning, may help new teaching approaches by providing clear, exciting, and engaging learning tools.

The adoption of innovative teaching strategies for smart education (Shi et al., 2019) is already critical in academic institutions all around the world. Traditional in-classroom education versus quality has almost had the same horizontal trend for decades, while teaching approaches based on smart pedagogy are progressively increasing the quality over the years (Uskov, Bakken, et al., 2017). As reported in van den Broek, 2012 and Uskov et al., 2018 some innovative teaching strategies and learning styles, include Active Learning (AL), Game-based learning (GBL), Learning-By-Doing (LBD), Challenge-based learning (CBL), Massive Open Online Courses (MOOC), Collaborative Learning (CL), Crowdsourcing-based Learning (CWL), Flipped Classroom (FC), Learning through Augmented and Virtual Reality (LAVR), and others. All the abovementioned approaches can extensively benefit from the use of advanced technologies to produce enhanced learning materials supporting smart education. 
The application of these innovative approaches to STEM (Science, Technology, Engineering and Mathematics) disciplines has already given good results in terms of both effective teaching strategies and learning skills (Corlu and Aydin, 2016). Rodríguez-Chueca et al., 2020, used FC and CBL for teaching sustainability and circular economy to Environmental Engineering students. The reversed approach of FC improves critical thinking, creativity, and collaborative work, while CBL actively simulates a real-world situation, open-ended problems that students must solve. Uskov et al., 2019 applied different smart educational approaches (FC, LBD, GBL, CL) to Computer Science teaching. The final goal was the assessment of the improvement perception in learning trends, through students' opinion on the specific teaching strategy adopted (CWL).

Other researches adopted the GBL approach (Zhao et al, 2018), also through LAVR (Zhang et al., 2017), for serious games development. Students' familiarity with computer games improves engagement and enjoyment for improved learning performances.

Furthermore, innovative teaching and appealing materials are useful to attract and involve future students towards STEM disciplines, since the demand of professionals able to face with the technological evolution is constantly increasing on the market.

\section{TEACHING GEOMATICS WITH SMART EDUCATION}

Geospatial Sciences and Geomatics represent a perfect example where blended pedagogical approaches may converge and be integrated. The experimental part has a fundamental role in teaching and knowledge transfer, from remote sensing to surveying activities. Researches on the application of smart approaches to such fields are so increasing in the last years, that all of the already cited approaches have been tested (Kosmatin Fras and Grigillo, 2016; Kravchenko et al., 2016; Hess et al., 2017; Ahlqvist and Schlieder, 2018; Haugsbakken et al., 2019; Gil-Docampo et al., 2019). The common goal is to actively involve students in the process of learning, by iterating field and class work, supported by multimedia tools, like videos, games, tutorials, MOOCs, and so on.

A continuous process of update and adoption of the most innovative pedagogical approaches has been carrying out by the GECO Lab for the last years (Tucci et al., 2018a; 2018b; 2019a; $2019 \mathrm{~b})$. The Laboratory has been involved in several technological and know-how transfer projects, at a national and international level, with audiences coming from very different backgrounds: from grade 3 up to $8^{4}$, from completely nonexperts in the field to academics and professionals. These experiences have fostered the development of specific didactic approaches and materials suitable for the different targets.

Amongst Geomatics and digitization technologies, the GECO Lab's attention has been focused on the application of effective methods for a correct diffusion of close-range photogrammetry. Digital photogrammetry, a reality- and image-based technique to produce 3D models, is rapidly spreading to wider and wider audiences: every person with a smartphone is a potential producer of photogrammetric models. This democratization may be ascribed to the availability and low cost of devices to acquire images and to the development of highly automated procedures for orientation and dense image matching. However, the outputs can be very different, from professional workflows that allow obtaining millimetric accuracy to fully automatic

\footnotetext{
${ }^{4}$ According to ISCED
}

apps for immediate (and blind) results. The final metric accuracy is strictly related to the purpose and field-of-use of the real-world digitization, which can be extremely varied and tailored for different needs: from documentation, monitoring, conservation of built heritage, artifacts, landscape, environment to the production of contents for videogames, tourism, art, additive manufacturing, communication and so on.

The appropriation of this technique from many people, thus not being a prerogative of only specialists anymore, entails some risks: the ease of use makes possible the production of 3D models without any critical awareness of the metric quality (Bitelli et al. 2019). One way to maintain a sort of control over this trend is education: correct information about photogrammetry, how to use it, and what can be produced. Therefore, it is necessary to find new ways for teaching the fundamentals of the discipline to beginners and to correctly build the skills of future specialists, as architects, engineers, archaeologists, urban planners, and in general of all the professionals that study territory and heritage, and their transformations.

"Promote and facilitate education, training, and technology transfer of the photogrammetry, remote sensing and spatial information sciences" is one of the aims of the ISPRS statutory mission, which has been financially supported by the Education and Capacity Building Initiatives since 2016. Our contribution will present the results of one of the funded projects within the 2018 program "Education and training resources on digital photogrammetry". The production of multimedia material for supporting smart educational approaches will be reported, as well as experiences on their application on the field.

\section{THE PROJECT}

\subsection{Aims}

The main aim of the project "Education and training resources on digital photogrammetry" has been the production of new educational resources, useful for supporting tutorials, workshops, seminars, and courses, for teaching the latest advances in digital photogrammetry with smart approaches. Multimedia educational tools about digital photogrammetry, like presentations, videos, guidelines, tutorials, and datasets have been focused on explaining theoretical concepts and describing practical activities. An extensive research on photogrammetry teaching materials has been carried out in order to choose the most relevant topics for the project purposes. In addition, the contents of the didactic materials can be suitable for several contexts, but they are notably meant for applications in Cultural Heritage surveying, documentation, risk assessment and restoration support. The produced resources have intentionally been not software-related, thus being suitable in different educational scenarios.

The combination of updated learning material and smart teaching approaches have been also tested on the field in different case studies. In fact, another objective of the project has been organizing the TCV pre-symposium tutorial "Ground based 3D modelling (Close range photogrammetry \& TLS)" during the ISPRS TCV Mid-Term Symposium in Dehradun ${ }^{5}$ (India, November 2018), as a test to apply the above-mentioned teaching methodologies and the produced educational resources. Finally, as a long-term contribution to the ISPRS Technical Commission $\mathrm{V}$ mission, the project outcomes may be shared with ISPRS community as a starting point to increase and update the Educational section of the ISPRS web site, hopefully boosting some other new contributions to cover different topics.

\footnotetext{
${ }^{5}$ www.isprstc5india2018.org
} 


\subsection{Proposed methodology}

Different educational strategies have been tested, as a combination of LBD, CL, CBL, and FC teaching approaches for both direct and distance learning. Despite engaging multimedia learning materials represent useful supports for the complex process of capacity building, they need to be integrated within these teaching strategies to be considered as smart education.

Researches (Dewey, 1916; Lesgold, 2001) and the authors' experience suggest that case-based projects (LBD) on specific issues result to be effective forms of know-how transfer. Students are encouraged to carry out practical activities, often related to local heritage, sustained by educational resources. The role of didactic material is to help students in retracing the steps of data acquisition and processing phases, but above all in understanding and evaluating the quality of obtained data, progressively acquiring the skills necessary to obtain results that are actually applicable for the protection and conservation of Cultural Heritage.

The key point of the LBD approach is active thinking through a continuous cycle of experience and reflection, thus limiting moments of passive reception of contents. The direct experience of carrying out a task fosters student to improve analytical and decision-making skills, internalize accountability, learn how to deal with real-life problems, develop team working and problem-solving skills.

The multidisciplinary backgrounds of the potential learners' groups suggest the adoption of blended smart teaching methodologies. A collaborative approach (CL) promotes large groups working together for the completion of a task or a project (see LBD approach) by actively using online multimedia tools and tutors' support, collaboration and interaction with teachers and other students, and building team-working approach for problem-solving as well as of individual accountability (NMC Horizon Report, 2014). The traditional image of the teacher that knows everything is then replaced by interaction where students give inputs and share their own knowledge, developing social skills and critical thinking through discussion and debate.

This collaborative approach can be further implemented by adding challenge-based teaching and learning strategies (CBL): the students propose solutions for real-world problems, by using everyday technologies and what they already know about the topic of the challenge (Nichols and Cator, 2008; Johnson et al. 2009). This framework involves students and teachers in an engaging way to achieve a shared common goal, by using both personal and team skills. A further incentive to foster learners' commitment, may be a final award for the best proposed solution or output, by peer-to-peer evaluations (Gil-Docampo et al., 2019).

Finally, the flipped classroom (FL) approach has also been tested. This method distributes in a different way how the time is spent in and outside class. The activities in presence are mainly devoted to practical activities, by using LBD and CBL, while the teacher provides supporting multimedia materials to be used outside. In this way, the time spent in class is effectively used to share information and interactive collaboration; the details of the concepts faced in the classroom can be learned and managed elsewhere, in complete autonomy or by asking the teacher's support (NMC Horizon Report, 2014)

\subsection{Target user groups}

The target groups consist of people interested in close-range photogrammetry technique for surveying of built and environmental heritage, like:

- students in civil, building and environmental engineering, architecture, archaeology, geology, geography, geospatial science, etc. to build future professionals able to proper use this and other Geomatics techniques for documentation, monitoring, conservation, and risk assessment. The in-depth level of the didactic material should be high, suitable for academic courses. A complete overview of the theory behind technologies and methods should be satisfied

- professionals wishing to acquire or update their skills, like surveyors with or without an academic degree. In this case, the supporting material should be more oriented towards practical approaches, with useful suggestions and good practices to follow in the phase of data collection and processing

- trainers who need to be trained for teaching photogrammetry in autonomy, as for example in technological transfer processes abroad. In this case a complete awareness of both theorical and practical concepts should be built. Distance support should be offered to follow trainers' progresses and help them if necessary

- completely non-experts who want to learn more about this technology because they would like to start using it for work or because they are just curious. In this case the level of the didactic material should be simple but not superficial, by always citing the importance of metric accuracy depending on the final goal

\section{EDUCATIONAL ACTIVITIES AND OUTCOMES}

\subsection{Multimedia supporting materials}

The contribution of supporting didactic materials for digital photogrammetry consists in improved learning of theory and practice by using the most up-to-date technologies: multimedia tools like videos and animations can help clarifying and visualizing theoretical concepts, making them more engaging. Furthermore, it is not always possible to go directly on the field for practical activities, thus multimedia tools can be used for illustrating the activities of a survey campaign.

Online didactic materials on close-range photogrammetry derive from different sources (academic $^{6}$, commercial ${ }^{7}$, non-profit organizations $^{8}$, and individual) and are available in several forms (online courses, MOOCs, websites, tutorials, videos, guidelines, etc.). Most of them consist of tutorials on the use of software, while there are fewer resources regarding the project design, the acquisition of images and data for producing reliable results and verify the metric quality of the outcomes.

For this reason, the attention has been focused on the production of resources which contents cover the topics listed below:

- production of digital images to produce effective and reliable 3D models

- photographic issues relevant in photogrammetry (image exposure, depth of field, etc.)

- describing how to fit the general approach to real cases, considering objects related to cultural heritage: buildings, statues, historical city centers, archaeological findings, etc.)

\footnotetext{
${ }^{6}$ www.newdev.eduopen.org

${ }^{7}$ www.3dflow.net, www.agisoft.com, www.autodesk.com

${ }^{8}$ www.culturalheritageimaging.org
} 
- the role of control measurements in a photogrammetric project

- acquisition of data on significative case studies

- organization of reference datasets (set of images, coupled with Ground Control Points GCPs, and examples of photogrammetric outcomes - 3D models, orthophotos, laser scanning data to allow comparison

4.1.1 Tutorials: The above-mentioned topics have been included in several tutorials, in the form of texts and presentations, calibrated on the different target user groups, mentioned in section 3.3. These didactic materials are useful tools for supporting the knowledge transfer on theoretical concepts in classroom, often to give an introduction before going on the field during workshops, seminars, and courses. Tutorials further represent reference materials the students can use out of the class, to improve their comprehension or retrace the activities done outside. An overall revision of the previous static materials, mainly in the form of presentations, has been carried out in order to improve clarity and engagement, thus preferring the use of videos, animations, guidelines, and images in respect to long texts (some examples in Figure 1a-d).

4.1.2 Videos: The following videos have been produced as supporting materials so far:

- "A general journey in photogrammetry - how to take photos", with practical guidelines on how to make imagebased 3D models, carefully concerning accuracy aspects. This video is an introduction to reality-based digitization through photogrammetry, showing basic geometrical principles, how to take photos, and photographic tips. The concepts are presented avoiding details about algorithms, and references to specific software as well, but giving information to produce good quality 3D models, also from a metric point of view

- "Fundamentals of photography for photogrammetry", about concepts of basic photography applied to photogrammetry, as how to correctly take photos by considering shooting parameters (ISO, shutter, and aperture), good practices in post-processing and other recommendations for better photo acquisitions suitable for photogrammetric purposes. This video is the first insight of a series, to deepen the introductory concepts presented in the above-mentioned video

- “Giovanni Pisano's pulpit in St. Andrea (Pistoia). Geomatics for study and conservation of the artwork", describing a real case study, where photogrammetry is part of an integrated survey for documentation of a complex small architecture with sculptural elements. The different phases and technologies used during the surveying process have been documented, by filming the activities and interviewing the operators involved. The main goal has been presenting the challenges and the difficulties in surveying such a complex object to produce a 3D model for structural analysis and to support the restoration project

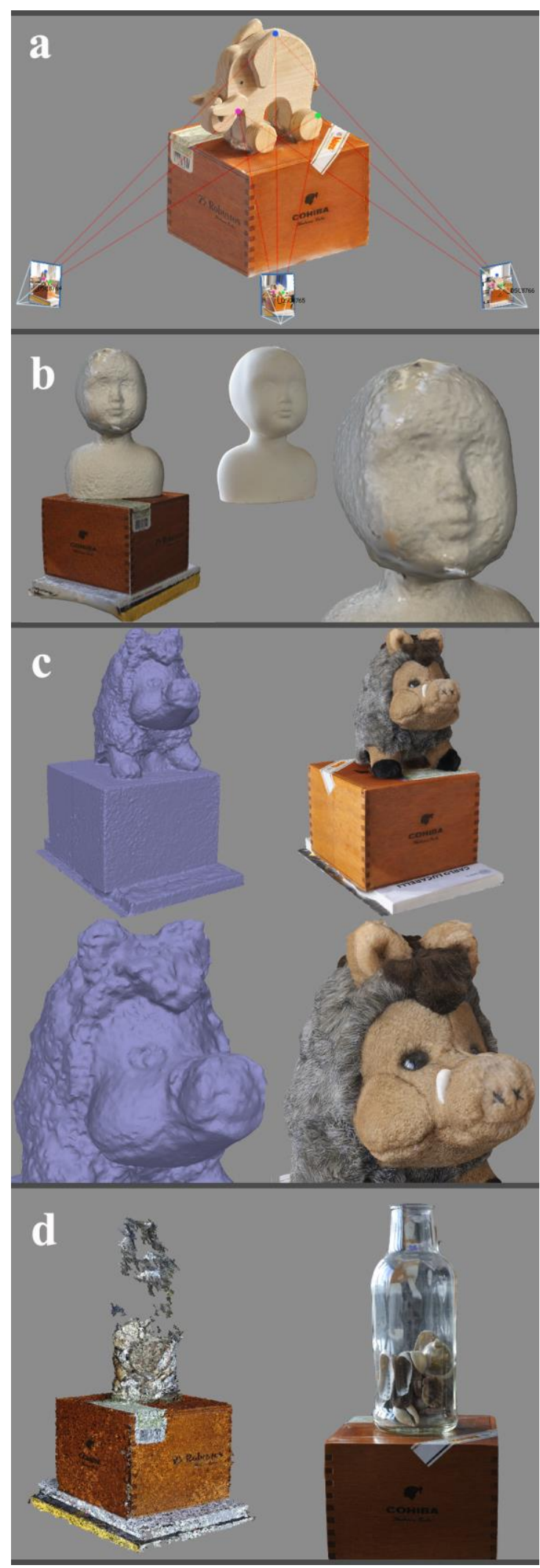

Figure 1. Examples of photogrammetric concepts represented with specifically prepared 3D models to show: a) images chief rays intersecting in the object space; difficult objects to be digitized by photogrammetry as for b) uniform textures, c) hairy objects, and d) transparent objects 
4.1.3 Datasets: The acquisition of data on the field is a useful activity in the learning process of Geomatics. When it is not possible doing practical activities in-situ, previously acquired data can be useful supporting tools. Datasets can be shared with students who have the chance to test and understand the workflows of data processing. Different software and approaches may be then used to produce $2 \mathrm{D}$ and $3 \mathrm{D}$ outputs, as for real conservation projects or other purposes. The produced datasets usually come from different sources (ground-based and aerial photogrammetry, Terrestrial Laser Scanning TLS, topography, GNSS), and they need to be integrated, thus allowing students understanding the limitations of each technique and the opportunities given by multi-source data integration.

\subsection{Experiences on smart education approaches}

4.2.1 ISPRS TCV pre-symposium tutorial: The first application of the supporting materials produced and of a selected smart educational approach was made during the threedays "Ground-based 3D Modeling (Close Range Photogrammetry \& TLS)" ISPRS TCV pre-symposium tutorial in Dehradun (India) on $17^{\text {th }}-18^{\text {th }}$ November 2017. Fifteen participants took part at the tutorial (master students, $\mathrm{PhD}$ students, researchers, and teachers), coming from different Countries (India, Thailand, Vietnam, Nepal, Mongolia, Bhutan), and with different backgrounds.

The heterogeneity of the participants in terms of both educational level and discipline provided an interesting opportunity for evaluating the effectiveness of the proposed teaching materials and approaches, as they were scholars who knew the overall problems of remote sensing but not specialized in Cultural Heritage. Almost all of them had any specific training in the use of photogrammetry and laser scanner.

Although the LBD teaching approach was used, the first day has been dedicated to introducing the topics of the tutorial, by using a beta-version of the supporting multimedia tools reported in section 4.1. The participants received essential information on photography for photogrammetry, SfM (Structure-from-Motion) close-range photogrammetry and TLS, thus being able to face the practical activities.

A significant case study for fieldwork was selected, in collaboration with local organizers, for boosting the interest of the tutorial participants. The headquarter of the Forest Research Institute (FRI) was recommended as the most representative historic built heritage of the city (Figure 2a).

The second day the participants were asked to plan a survey project, after a careful analysis of the location, and always supported by the tutors. Since students were not familiar with Cultural Heritage documentation projects, the requirements for a tailored photogrammetric project were first illustrated, by identifying a proper Ground Sample Distance (GSD) and the most appropriate network design. The proper focal length, distance from the object, and baseline were then chosen, by considering the site characteristics, and the available equipment. All exposure parameters were selected according to lighting conditions. The target positions were then chosen, considering that the object would had been acquired simultaneously with TLS. The integration of both technologies allowed to train the participants also in the use of the TLS and to compare the results obtained from two different sources (Figure 2a).

The field experience was focused on the documentation of the facades of the central court, with particular attention to the left wing, where the vaulted portico at the ground floor was surveyed (Figure 2b). In order to show other possible applications of terrestrial photogrammetry in a different field, for example to the human body acquisition, 3D models of the faces of some students were also performed (Figure 2c).

During the last day of the tutorial, there was an introduction to data processing, and the results of the Forest Research Institute survey were presented and discussed. Photogrammetric data were compared with laser scanner results for assessing their quality. Although the peculiarities and differences between the two methods had already been explained from a theoretical point of view, it was much more effective comparing the acquired data and outputs of a project personally carried out. As requested by the participants, some of their previous closerange photogrammetry projects in other fields were also presented for comparing and discussing the results with the tutors. A final feedback on the overall experience was asked to the participants in order to better calibrate the produced material and to evaluate the adopted teaching approach.

The students learned how geomatic techniques can be used to carry out Cultural Heritage documentation projects, and they acquired basic skills in close-range photogrammetry. In addition, a new dataset was produced, by documenting an interesting built heritage case study and by obtaining data useful for structural assessment, as already published in Tucci et al. $2019 b$.

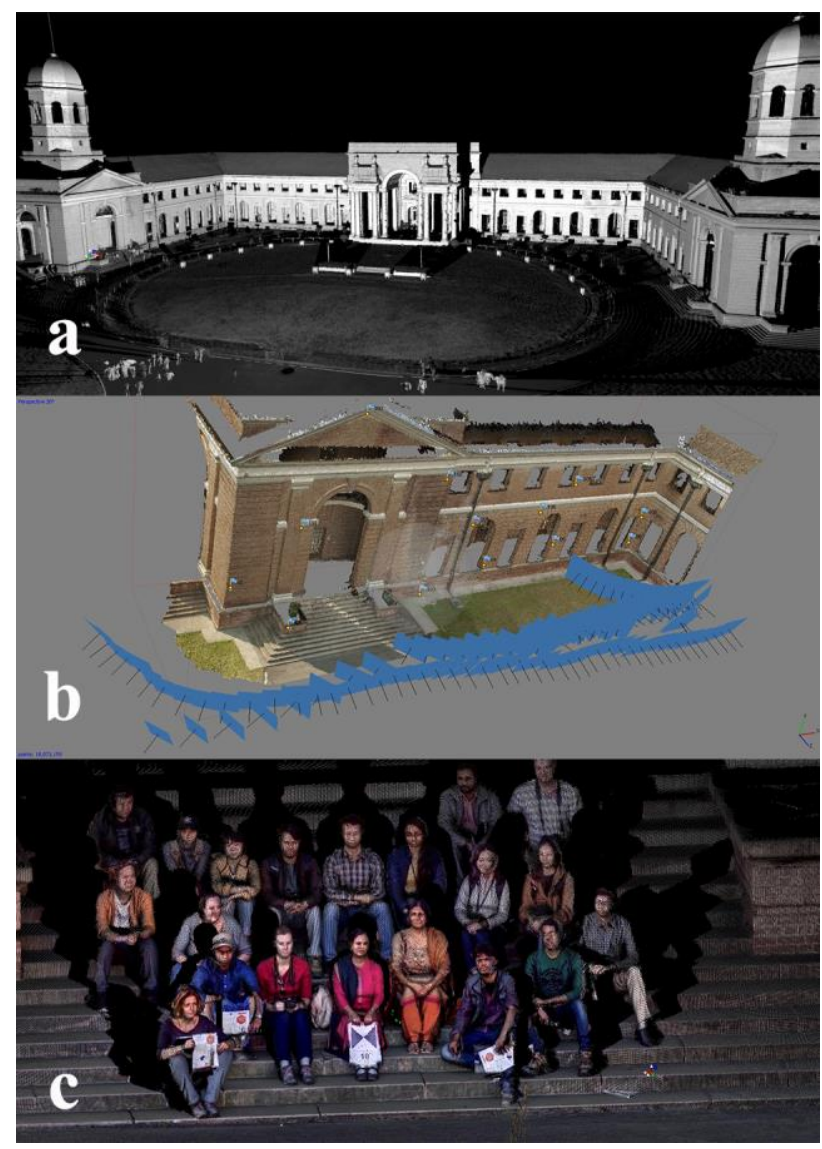

Figure 2. Surveying activities during the second day of the presymposium tutorial "Ground-based 3D Modeling (Close Range

Photogrammetry \& TLS) at the Forest Research Institute headquarter in Dehradun (India).

a) The facades of the building central court were surveyed by TLS; b) ground-based photogrammetry was used for the digitization of the left wing of the building and the vaults; c) a group point cloud of the participants obtained by TLS 
4.2.2 Workshop "The New Jerusalem in 3D": The didactic paradigm of Dehradun tutorial was tested again in a workshop held from $23^{\text {rd }}$ to $26^{\text {th }}$ March 2019, for surveying part of the socalled New Jerusalem of San Vivaldo (Montaione, Italy). In this case the participants, coming from Cuba and Greece, were previously trained on TLS and photogrammetry, thus the workshop aimed at improving their practical skills. The didactic materials were further tested to assess their clarity and effectiveness in front of an audience with intermediate skills. A combination of CL and LBD teaching approach was used during the phases of data collection and processing of the workshop.

The workshop was carried out within the Innova Cuba project (see Tucci et al. 2018a). The process of technological transfer with Cuban partners has being carried out from 2011 with several missions of the GECO Lab staff to Cuba. The participants, previously trained during a two-weeks tutorial in Havana $\left(20^{\text {th }}\right.$ January $-4^{\text {th }}$ February 2018$)$, had the chance to see and use instruments and technologies difficult to bring them, such as drones and GNSS, thus completing the know-how transfer. They also applied the acquired knowledge on peculiar objects of Italian history, by directly carrying out parts of the survey.

One goal of the Innova Cuba project is to train technicians who should become trainers in turn in their Country, with balanced transfer of theory (Italian mission to Cuba) and practice (Cuban mission to Italy). The results of this knowledge transfer process have already proven to be effective, since the participants are autonomously carrying out surveying projects. Moreover, they organized a first test event on crowdsourced photogrammetry in Havana. This event was targeted to non-expert audience with any previous knowledge on the topic, where the trainers used the same material and guidelines provided them during the previous mission, and provided basic assistance for the data acquisition phase of images useful for a photogrammetric process (carried out later by professional operators).

4.2.3 Datasets produced during courses: The practical activities conducted during the academic courses on Geomatics at the University of Florence, often leads to data acquisition on different case studies depending on the course and the year. These courses often foresee practical activities on the field, tailored for the different needs of the students, belonging to Engineering, Architecture, Archaeology and Geography Schools. Some of these courses are held in the form of laboratories, thus being possible applying the LBD approach for a case-based project.

As an example, a dataset on a significant historical building, the Spedale di Sant'Antonio in Lastra a Signa near Florence, was collected in 2018. The same case study has been the object of study for several courses during the same and the following years. In the academic year 2019-2020 the same dataset was used for the courses "Geomatics for the conservation of Cultural Heritage" (one in Italian and one in English) at the School of Architecture, and for "Topography and Geographic Information Systems" at the School of Engineering. Therefore, the didactic materials have been tested with students with different cultural backgrounds and coming from different Countries.

The dataset includes terrestrial photogrammetric images, measurements of ground control points and relative documentation, laser scanner acquisitions for comparing and verifying the quality of the results, as well as photographic and video recordings of the survey operations. Moreover, students have been requested to make short videos for illustrating the acquisition of photogrammetric data and their processing as a feedback for understanding which aspects they considered more challenging and significant.
4.2.4 3DHackathon: The event involves participants with no previous knowledge in the use of photogrammetry to produce $3 \mathrm{D}$ digital models, with a combination of $\mathrm{CL}, \mathrm{LBD}$ and $\mathrm{CBL}$ teaching strategies.

A collaborative approach allows to experience advantages in terms of information, innovation and identification, through a five-day program, alternating theoretical activities in the classroom and practical ones on the field. In particular, the first day was dedicated to the introduction of the basics of photogrammetry by providing participants with supporting guidelines and tutorial to continue, on the second day, with the acquisition of images on an agreed theme (LBD).

The third and fourth days were used to process the data, also presenting insights on specific topics, to conclude the fifth day with the presentation of the results obtained and the selection of the best 3D model (CBL).

The first edition of 3DHackathon was organized on $3^{\text {rd }}-7^{\text {th }}$ February 2020. Fifteen participants of grade ISCED 3 came from the Higher Education Institute B. Varchi (Montevarchi, Italy) and the acquisitions were carried out at the Paleontological Museum of Montevarchi. The participants were organized in four teams, each one assigned with a paleontological find to be digitized in-situ by photogrammetry. The selection of the objects was carefully carried out in collaboration with the Museum Director, by considering the most representative for their needs but suitable for photogrammetric projects.

The 3D models of the same objects were produced with images coming both from professional cameras and from the participants' smartphones, to compare the results. The last day the students presented the final outputs to the tutors and their classmates, who voted for the best 3D model. The results are available on the platform Sketchfab ${ }^{9}$ (reported in Figure 3).

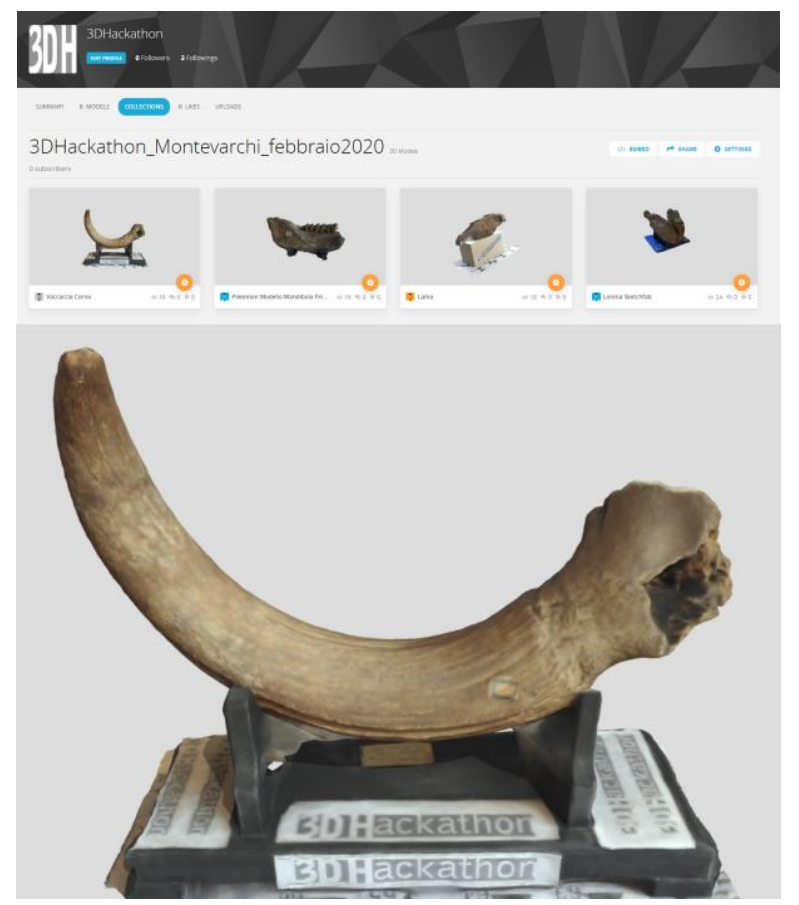

Figure 3. The four photogrammetric models of the paleontological finds from the Palaeontological Museum of Montevarchi (Italy). The bovine horn was selected as the best model of the 3DHackathon first edition

${ }^{9}$ www.sketchfab.com/3DHackathon/collections/3dhackathon_montevar chi_febbraio2020 


\subsection{Further approaches for online and distance learning}

4.3.1 The D3MOBILE Metrology World League: The project is an international championship (Gil-Docampo et al., 2019), which introduces secondary students (grades ISCED 1 and 2) to the disciplines of photogrammetry and metrology through a project-based e-Learning methodology. The use of well-known technologies by the students, such as their own mobile devices (smartphones or tablets) and photogrammetric free apps and software, allows to develop educational procedures based on reality-based digitization that are attractive and challenging for them (CBL approach).

The main goal is the implementation of a methodology that can be adapted to daily classwork at the high school level anywhere in the world (as for FC). Particularly, the contents of the proposed trials are designed to cover key topics like the photogrammetric principles for $3 \mathrm{D}$ reconstruction, common problems (e.g. reflective objects and blurring), model texturing, etc., which participants are expected to carry out on their own with tutors' support (LBD).

The project "Development of educational content for the "D3MOBILE Metrology World League" has been financially supported as part of 2020 ISPRS Education and Capacity Building Initiatives, as joint venture between the University of Santiago de Compostela (Spain), and the University of Florence (Italy). This collaboration can foster networking activities, to expand the diffusion of this program also among Italian schools and other International Institutions (like ISPRS, ICOMOS, CIPA Heritage Documentation), and communities. Furthermore, an Italian version of the website ${ }^{10}$ and of the supporting materials (texts and videos) may ease the dissemination of the project, by also implementing the already available resources with the ones reported in section 4.1.

The 2020 eighth edition of the championship is currently ongoing, thus highlighting the benefits and the potentialities of ODL, also as a future established resource.

4.3.2 Distance academic learning at the time of a global pandemic: The rapid reorganization to assure the continuity of academic didactics during the current lock-down phase, has requested the adoption of ODL, in total substitution of the frontal approach.

This substantial chance required resorting to similar approach as for FL in Geomatics courses, by providing students multimedia materials (video-lessons and seminars, videos, bibliography, tutorials, etc.) they can consult anytime on learning platforms, like Moodle ${ }^{11}$ (a Course Management System), and other interactive tools ${ }^{12}$. The students have a direct interaction with the teacher once a week, for a live lesson, where they can ask questions and clarify their doubts (Figure 4).

The students are also divided into groups, to improve teamwork for the production of reports on shared topics, to be discussed live through videoconferences. Practice exercises are also proposed, to encourage individual work, by using previously acquired datasets (see 4.1.3) or by asking students to acquire new data with their own devices at home, to produce photogrammetric 3D models. A final award is also planned before the end of the course, after peer-to-peer evaluations of the produced 3D models, that will be published on Sketchfab.

\footnotetext{
${ }^{10}$ www.d3mobile.es

${ }^{11}$ www.moodle.org

12 www.mentimeter.com
}

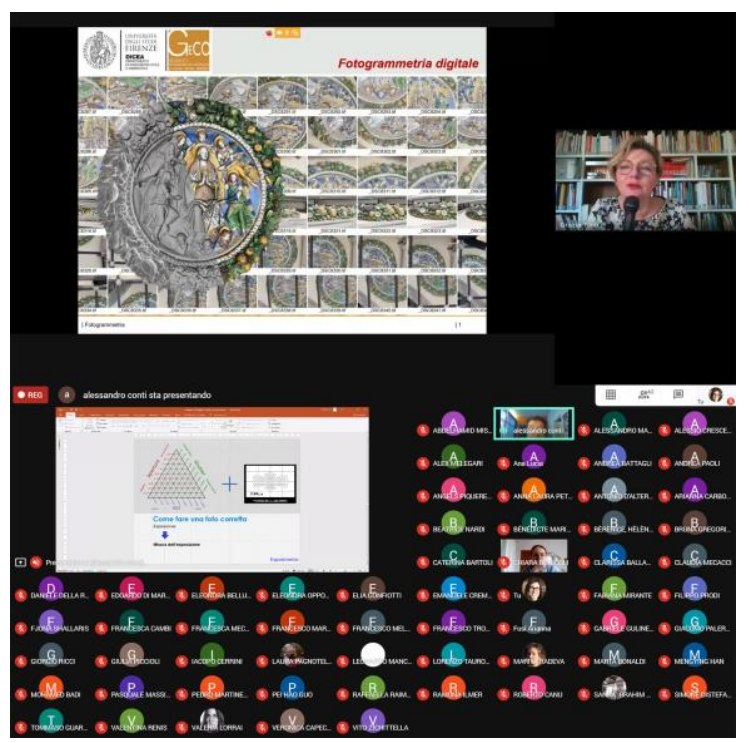

Figure 4. Live lessons of photogrammetry in Geomatic courses. Interaction between teachers and students is strongly encouraged for didactic support, discussions on shared topics, and to present the results of practice exercises

\section{CONCLUSIONS AND FUTURE WORKS}

The pedagogical implementation of educational resources and the adoption of smart teaching approaches is a fundamental step in the diffusion of Geomatic techniques among wider audiences. The experiences carried out show the effectiveness of blended educational methods supported by captivating didactic materials, such as tutorials, guidelines, videos and datasets. Different teaching and learning approaches were adopted thus promoting capacity building at different levels of professionals, educators and students, to develop effective teaching methods, to support distance learning programmes. Students acquired new practical skills on the design of photogrammetric projects together with understanding the theoretical principles of digital photogrammetry. The teaching strategies and the produced materials proved to be effective both for direct practical activities and for online and distance learning.

The next steps will be the implementation of multimedia supporting materials, by producing insights for specific topics, as well as the use of these educational resources for web-based and distance learning. Blended smart educational strategies will be further tested, with particular focus on the CBL approach, through the organization of competitions, both at national (3DHackathon) and international level (D3MOBILE), where students have to produce correct and purpose-oriented 3D models, with more awareness of the potentials and limits of photogrammetry.

\section{ACKNOWLEDGEMENTS}

The project has been an international collaboration between the Department of Civil and Environmental Engineering of the University of Florence (Italy), Faculty of Technology of CEPT University (India), Kensemble Tech Labs Gandhinagar, Gujarat (India) and California Polytechnic State University (USA). The authors wish to thank the co-investigators of the project: Prof. Anjana Vyas, Dr. Vikram Sorathia and Prof. Satwant Rihal. The authors also thank Francesca Panighini of the GECO Lab for her support during the tutorial activities in Dheradun (India), and all the participants involved in courses, workshops and seminars for their interest and collaboration. 
This work has been carried out within the GAMHer project: Geomatics Data Acquisition and Management for Landscape and Built Heritage in a European Perspective (PRIN2015 n.2015HJLS7E).

\section{REFERENCES}

Ahlqvist, O., and Schlieder, C., 2018: Geogames and Geoplay, Springer, Cham. doi:10.1007/978-3-319-22774-0

Bitelli, G., Balletti, C., Brumana, R., Barazzetti, L., D'Urso, M. G., Rinaudo, F., and Tucci, G., 2019. The GAMHer Research project for metric documentation of Cultural Heritage: current developments. Int. Arch. Photogramm. Remote Sens. Spatial Inf. Sci., XLII-2/W11, 239-246. https://doi.org/10.5194/isprsarchives-XLII-2-W11-239-2019, 2019.

Corlu M.A., Aydin, E., 2016. Evaluation of Learning Gains Through Integrated STEM Projects. Int. J. Educ. Math. Sci. Technol. 4 (1). doi:10.18404/ijemst.35021

Dewey, J., 1916. Democracy and Education. Macmillan, US.

Gil-Docampo, M., Ortiz-Sanz, J., Rego-Sanmartin, T., ArzaGarcia, M., 2019. A world wide web-based practice that disseminates photogrammetry: Inspiring secondary students to pursue geomatics careers. IEEE Geosci. Remote Sens. Mag. 7, 86-97. doi:10.1109/MGRS.2018.2876565

Haugsbakken, H., Nykvist, S., Lysne, D.A., 2019. The Need to Focus on Digital Pedagogy for Online Learning. Eur. J. Educ. 2 (3). doi:10.26417/ejed.v2i3.p25-31

Hess, M., Garside, D., Nelson, T., Robson, S., Weyrich, T., 2017. Object-Based Teaching and Learning for a Critical Assessment of Digital Technologies in Arts and Cultural Heritage. ISPRS - Int. Arch. Photogramm. Remote Sens. Spat. Inf. Sci. XLII-2/W5, 349-354. doi:10.5194/isprs-archives-XLII2-W5-349-2017

Johnson, L.F, Smith, R.S., Smythe, J.T., Varon, R.K., 2009. Challenge-Based Learning: An Approach for Our Time. The New Media Consortium, Austin, Texas

Kosmatin Fras, M., Grigillo, D., 2016. Implementation of active teaching methods and emerging topics in photogrammetry and remote sensing subjects. Int. Arch. Photogramm. Remote Sens. Spat. Inf. Sci. 41, 87-94. doi:10.5194/isprsarchives-XLI-B6-872016

Kravchenko, I., Luhmann, T., Shults, R., 2016. Concept and practice of teaching technical university students to modern technologies of 3D data acquisition and processing: A case study of close-range photogrammetry and terrestrial laser scanning. Int. Arch. Photogramm. Remote Sens. Spat. Inf. Sci. 41, 65-69. doi:10.5194/isprsarchives-XLI-B6-65-2016

Lesgold, A.M., 2001. The nature and methods of learning by doing. American Psychologist, 56(11), 964-973. doi.org/10.1037/0003-066X.56.11.964

Nichols, M.H., Cator, K., 2008. Challenge Based Learning White Paper. Cupertino, California: Apple, Inc.

Rodríguez-Chueca, J., Molina-García, A., García-Aranda, C., Pérez, J., Rodríguez, E., 2020. Understanding sustainability and the circular economy through flipped classroom and challenge- based learning: an innovative experience in engineering education in Spain. Environ. Educ. Res. 26, 238-252. doi:10.1080/13504622.2019.1705965

Shi, W., et al., 2019. Review on Development of Smart Education. IEEE International Conference on Service Operations and Logistics, and Informatics (SOLI), Zhengzhou, China, 2019, 157-162. doi: 10.1109/SOLI48380.2019.8955052

The NMC Horizon Report, 2014 - Higher Education Edition. The New Media Consortium, Austin, Texas

Tucci, G., Conti, A., Fiorini, L., Mei, F., Parisi, E.I., 2018a. Digital photogrammetry as a resource for Cuban cultural heritage: Educational experiences and community engagement within the Innova Cuba project. Int. Arch. Photogramm. Remote Sens. Spat. Inf. Sci. 42, 37-44. doi:10.5194/isprs-archives-XLII5-37-2018

Tucci, G., Conti, A., Fiorini, L., Panighini, F., Parisi, E.I., 2018b. Education and training resources on digital photogrammetry. Int. Arch. Photogramm. Remote Sens. Spat. Inf. Sci. 42, 45-50. doi:10.5194/isprs-archives-XLII-5-45-2018

Tucci, G., Parisi, E.I., Conti, A., Corongiu, M., Fiorini, L., Panighini, F., 2019a. Educational and training experiences in geomatics: Tailored approaches for different audience. ISPRS Ann. Photogramm. Remote Sens. Spat. Inf. Sci. 42, 1097-1104. doi:10.5194/isprs-Archives-XLII-2-W11-1097-2019

Tucci, G., Rihal, S., Betti, M., Conti, A., Fiorini, L., Kovacevic, V.C., Bartoli, G., 2019b. Ground based 3D modelling (photogrammetry and TLS) - Survey, documentation and structural assessment of XX century cultural heritage in India A case study of the masonry vaults in Dehradun. ISPRS Ann. Photogramm. Remote Sens. Spat. Inf. Sci. 42, 1105-1111. doi:10.5194/isprs-Archives-XLII-2-W11-1105-2019

Uskov, V.L., Bakken, J.P., Aluri, L., 2019. Crowdsourcingbased learning: The effective smart pedagogy for STEM education. IEEE Glob. Eng. Educ. Conf. (EDUCON), 2019, 1552-1558. doi:10.1109/EDUCON.2019.8725279

Uskov, V.L., Bakken, J.P., Aluri, L., Rachakonda, R., Rayala, N., Uskova, M., 2018. Smart pedagogy: Innovative teaching and learning strategies in engineering education. IEEE World Eng. Educ. Conf. (EDUNINE), Buenos Aires, 2018, 1-6. doi:10.1109/EDUNINE.2018.8450962

Uskov, V.L., Bakken, J.P., Penumatsa, A., Heinemann1, C. and Rachakonda R. Smart Pedagogy for Smart Universities, 3-16. In Uskov, V.L., Howlett, R.J., Jain, L.C., 2017: Smart Education and e-Learning. Springer, Cham.

van den Broek, G., 2012. Innovative Research-Based Approaches to Learning and Teaching. OECD Education Working Papers, 79. doi.org/10.1787/5k97f6x1kn0w-en

Zhang, L., et al., 2017. On the exploration of game-based learning in STEM education with the development and application of virtual reality course modules. ASEE Annu. Conf. Expo. Conf. Proc. 2017. doi:10.18260/1-2-28717

Zhao, D., et al., 2018. A Large-Scale Pilot Study on GameBased Learning and Blended Learning Methodologies in Undergraduate Programming Courses. EDULEARN18 Proc. 1, 3716-3724. doi:10.21125/edulearn.2018.0948 